\title{
In vitro and in vivo studies on anti-malarial activity of Commiphora africana and Dichrostachys cinerea used by the Maasai in Arusha region, Tanzania
}

Prisca A. Kweyamba', Denis Zofou², Noella Efange ${ }^{2}$, Jules-Clement N. Assob², Jovin Kitau and Mramba Nyindo ${ }^{1 *}$

\begin{abstract}
Background: Traditional medicinal plants are one of the potential sources of anti-malarial drugs and there is an increasing interest in the use and development of traditional herbal remedies for the treatment of malaria and other ailments. This study was carried out with the aim to investigate the phytochemical screening, cytotoxic effect and antiplasmodial activities of Dichrostachys cinerea and Commiphora africana. Both plants are used by the Maasai in Tanzania in suspected malaria and other diseases. No previous work appears to have investigated the potential antimalarial activity of the two plants.

Methods: This study aimed to investigate the in vitro anti-malarial activity of methanol and dichloromethane extracts of the two plants against chloroquine sensitive (D6) and chloroquine resistant (Dd2) strains of Plasmodium falciparum. The anti-malarial property was assessed by the lactate dehydrogenase method (pLDH). The in vivo antimalarial study was carried out using the Peters' 4-day suppressive test in Plasmodium berghei in Balb/c mice. Cytotoxic tests were carried out using monkey kidney epithelial cell line in [3(4,5-dimethylthiazol-2-yl)-2,5-diphenyltetrazolium bromide] (MTT) assay. Qualitative phytochemical screening was carried out using standard methods of analysis.

Results: The phytochemical screening of plant extracts revealed the presence of alkaloids, flavonoids, tannins, steroids, triterpenoids, glycosides and saponins. However, alkaloids were absent in most plant extracts. The dichloromethane extracts of C. africana (stem bark); D. cinerea (stem bark) and methanol extracts of D. cinerea (whole stem) all showed promising in vitro anti-malarial activities. All other extracts did not show any significant anti-malarial activity. The two most promising extracts based on in vitro studies, DCM extracts of C. africana (stem bark) and D. cinerea (stems bark), equally exhibited very significant anti-malarial activities in the mouse model. They exhibited parasite suppression rates of 64.24 and $53.12 \%$, respectively, and considerable improvement in weight and survival rate. Most plant extracts were not cytotoxic except for DCM extract of D. cinerea (whole stem) $C_{50}(29.44 \mu \mathrm{g} / \mathrm{mL}$ ).

Conclusion: The findings of this study provide scientific evidence supporting the traditional use of the plants in the treatment of malaria by the Maasai in Arusha region, Tanzania. Consequently, further work including bioassay-guided fractionation and advanced toxicity testing may yield new anti-malarial drug candidates from the two plants.
\end{abstract}

Keywords: Phytochemical screening, Commiphora africana, Dichrostachys cinerea, Antimalarial and cytotoxicity

\footnotetext{
*Correspondence: mnyindo2002@yahoo.co.uk

${ }^{1}$ Department of Parasitology and Entomology, Kilimanjaro Christian

Medical University College, P. O. Box 2240, Moshi, Tanzania

Full list of author information is available at the end of the article
} 


\section{Background}

Malaria is a potentially fatal tropical disease that is caused by a Protozoa of the genus Plasmodium. Of species of the parasites that affect humans, Plasmodium falciparum is by far the most virulent. The 2017 World Health Organization (WHO) Malaria report estimated 216 million cases of malaria and 445,000 deaths worldwide, with $90 \%$ of cases and $91 \%$ of deaths affecting the WHO African region $[1,2]$. Tanzania has entered a new era of malaria control with a realistic possibility to reduce malaria prevalence to less than $1 \%$ by 2020 through the national malaria strategy plan [3]. However, the prevalence of malaria in Tanzania has risen from 9\% in 20112012 to $14 \%$ in $2015-2016$, with the highest risk being areas close to the Lake zone and in rural settings [4].

The battle against malaria is becoming a serious challenge due to emergence of $P$. falciparum strains resistant to all anti-malarial drugs, including artemisinin-based combinations [2]. Therefore, there is a need to continuously identify new chemical compounds with anti-malarial activity. For decades, medicinal plants have played an important role in malaria treatment with the discovery of two major drugs, quinine and artemisinin that are used worldwide. Thus, medicinal plants have a great potential to provide new anti-malarial substances. It is also estimated that $80 \%$ of the population in developing countries depend on medicinal plants to meet their primary health care needs [5].

In Tanzania, scientific investigations have shown that over 100 plant species are used mainly by the rural population for the treatment of malaria, whereby some have been reported to have significant anti-malarial activity, but not many have been documented and only a few have been tested for anti-malarial activity [6]. The present study aimed at screening crude extracts from two widely used plants by the Maasai namely, Commiphora africana (Family Burseraceae) and Dichrostachys cinerea (Family Fabaceae) for their traditional use as anti-malarial.

\section{Methods}

\section{Collection of plant materials}

Stem bark and whole stem of both D. cinerea and C. africana were collected in Monduli district, Arusha region in Tanzania in October 2017. The botanic identification of the specimens was confirmed by a qualified botanist at the Tanzania National Herbarium in Arusha, where vouchers No PAK 001 and PAK 002 were deposited.

\section{Plant extraction}

For each plant sample, $60 \mathrm{~g}$ of dried ground plant material was repeatedly extracted in $1000 \mathrm{~mL}$ of dichloromethane and methanol in a 1:1 ratio $(\mathrm{v} / \mathrm{v})$. Plant extracts were filtered with Whatman Grade 1 filter paper, and the solvent was concentrated to dryness under reduced pressure using a BÜCHI R-200 rotavapor. The dry extracts were weighed, transferred into vials and stored at $-20{ }^{\circ} \mathrm{C}$ for further analysis.

\section{Phytochemical analysis}

Preliminary phytochemical analysis of plant extracts was performed to screen the plants for selected phytoconstituents including; alkaloids, steroids, cardiac glycosides, flavonoids, tannins and saponins using standard methods with some modifications [7-10].

\section{Plasmodium falciparum culture and maintenance}

A continuous culture of $P$. falciparum malaria parasites was established using the method described by Trager and Jensen with some modifications [11, 12]. The Plasmodium strains used were: D6 (chloroquine sensitive strain) and Dd2 (chloroquine resistant strain), isolated from Sierra Leone and Thailand, respectively. Parasites were grown in uninfected $\mathrm{O}+\mathrm{RBCs}$ as host cells and maintained in RPMI-1640 medium which was supplemented with $2 \mathrm{mg} / \mathrm{mL} \mathrm{NaHCO}_{3}, 10 \mu \mathrm{g} / \mathrm{mL}$ hypoxanthine, $2 \mathrm{mg} / \mathrm{mL}$ glucose, $1 \%$ albumax II and $10 \mu \mathrm{g} / \mathrm{mL}$ gentamicin. The culture was maintained at $37^{\circ} \mathrm{C}$ in a $\mathrm{CO}_{2}$ incubator. Parasitaemia was determined qualitatively and quantitatively using a fluorescent microscope (DAPI) and light microscopy (Giemsa stain).

\section{In vitro antiplasmodial activity}

In vitro antiplasmodial activity of the plant extracts was done in 96 well plates. Wells with parasitized red blood cells and without plant extract served as negative controls whereas wells containing cultures with chloroquine diphosphate served as positive controls. The plates containing parasite cultures were incubated for $48 \mathrm{~h}$ at $37^{\circ} \mathrm{C}$ in a $\mathrm{CO}_{2}$ incubator. After $48 \mathrm{~h}$ of incubation, the plates were frozen overnight at $-20{ }^{\circ} \mathrm{C}$ and antiplasmodial activity was assessed using the parasite lactate dehydrogenase (pLDH) assay that was previously described [12, 13]. The pLDH assay generated optical density values at various concentrations of the plant extracts using the Graphpad prism version 6 software (https://www.graph pad.com/scientific-software.html). A log dose response curve was generated and used to determine $\mathrm{IC}_{50}$ and $\mathrm{CC}_{50}$. Each product was tested in duplicate and the $\mathrm{IC}_{50}$ and $\mathrm{CC}_{50}$ values obtained from the duplicates were pooled and expressed as geometric means and standard deviations. The independent sample t-test was used to compare mean $\mathrm{IC}_{50}$ of anti-malarial activity between plant extracts using STATA version 13 (software StataCorp, College Station, TX, USA). 


\section{Cytotoxicity}

Cytotoxicity of each plant extracts was assessed on LLCMK2 monkey kidney epithelial cells. The cells were cultured in DMEM medium which was supplemented with $10 \%$ fetal bovine serum and $10 \mathrm{mg} / \mathrm{mL}$ of penicillinstreptomycin. The cells were then seeded in 96 well plates at 10,000 cells per well in $100 \mu \mathrm{L}$ culture medium. The cells were incubated for $48 \mathrm{~h}$ at $37^{\circ} \mathrm{C}$ in a $\mathrm{CO}_{2}$ incubator until they reached a level of confluence. After $48 \mathrm{~h}$, the medium was completely removed from the wells by inverting the microtiter plate and by tapping it on a sterile filter paper. The medium was then replaced with $100 \mu \mathrm{L}$ of fresh culture medium, followed by $100 \mu \mathrm{L}$ of crude plant extract $(1000 \mu \mathrm{g} / \mathrm{mL})$ in row $\mathrm{H}$ of the 96 well plate and serially diluted twofold to give concentrations ranging from 500 to $7.8125 \mu \mathrm{g} / \mathrm{mL}$. Row A of the 96 well plate served as control wells, whereby the negative control contained culture medium and LLC-MK2 cells without plant extract (100\% growth). The cells were maintained at $37^{\circ} \mathrm{C}$ in a $\mathrm{CO}_{2}$ incubator before determining their viability by using the MTT assay as previously described [6].

\section{In vivo pharmacological studies}

\section{Experimental animals and parasite}

Balb/c albino mice (Male and Female) aged 6-8 weeks and weighing 15-32 g used for this study, were provided by the Animal Breeding Unit of the Medical Research and Applied Biochemistry Laboratory (Drug Discovery and Development Research Unit) at the University of Buea. They were maintained at a room temperature of about $25{ }^{\circ} \mathrm{C}$ and 12:12 light/dark cycle, with food and water given ad libitum. All experiments were conducted with regards to the internationally accepted laboratory animal use, care and guidelines. The project proposal and SOPs were reviewed and approved by the University of Buea Institutional Ethics Review Board for Animal Use.

The lethal strain of Plasmodium berghei was kindly donated by BEI-Resources, Manassas, USA. To maintain the parasite, weekly serial passage of blood from infected mice to non-infected mice were performed [14].

\section{Parasite inoculation}

Donor albino mice previously infected with $P$. berghei and having parasitaemia level of $20-30 \%$ were used. The donor mice were anesthetized and sacrificed by opening the thoracic region in order to expose the heart. Blood was collected by cardiac puncture into heparinized vacutainer tube containing $0.5 \%$ trisodium citrate. Physiological saline $(0.9 \%)$ was used to dilute the blood based on parasitaemia level of the donor mice [15].

\section{In vivo suppressive test of Plasmodium berghei}

The 4-day suppressive test was used to measure the schizonticidal activity of the bioactive extracts and controls against $P$. berghei infected Balb/c mice, following a method described by Peters et al. [16], with some modifications [6]. In brief, infected mice were randomly divided into four groups of 5 each by weight. Treatment started $3 \mathrm{~h}$ after mice had been inoculated with the parasite on day 1 and then continued daily for 4 days (that is from day 1 to day 5). For each extract, animals received daily oral dose of $400 \mathrm{mg} / \mathrm{kg}$ day in $100 \mu \mathrm{L}$ phosphate buffer saline (PBS), $\mathrm{pH}$ 7.4. The positive control-group received $10 \mathrm{mg} / \mathrm{kg}$ body weight quinine orally per day, while the negative-control group animals were administered 100 $\mu \mathrm{L}$ of PBS. The survival rate was monitored on a daily basis in all groups for 28 days post-inoculation. On day 5 , Giemsa-stained thin blood smears were prepared from the tail of each animal to determine parasitaemia and percentage inhibition [17]. The percentage of parasite growth suppression (PGS) was estimated using the following equation:

$$
\mathrm{PGS}=100 \times[(A-B) / A]
$$

where $A$ is the average parasitaemia of the negative-control group and $B$ corresponds to the parasitaemia of the test group. The mean survival time for each group was determined in each group over a period of 28 days.

\section{Results}

\section{Preliminary phytochemical screening}

Preliminary phytochemical screening results of $D$. cinerea and C. africana extracts which were tested for eight selected phytoconstituents are summarized in Table 1. MeOH extracts of both plants showed presence of cardiac glycosides, flavonoids, tannins, triterpenoids and saponins. However, presence of alkaloids was only observed in C. africana extracts. Steroids were absent in all $\mathrm{MeOH}$ extracts. DCM extracts had appreciable levels of steroids, saponins and flavonoids. Surprisingly, these extracts did not contain any tannins, triterpenoids and alkaloids.

\section{In vitro antiplasmodial activity and cytotoxicity of plant extracts from Dichrostachys cinerea and Commiphora africana}

Table 2 shows the in vitro antiplasmodial activity of all plant extracts prepared from the selected plants, as well as their cytotoxic effect on LLC-MK2 cells. Of the eight extracts tested, DCM extracts of C. africana stem bark and $D$. cinerea whole stem showed promising antiplasmodial activity $\left(\mathrm{IC}_{50}=4.54 \pm 1.80 \mu \mathrm{g} / \mathrm{mL}\right.$ and $11.47 \pm 2.17 \mu \mathrm{g} / \mathrm{mL}$, respectively) against D6 strain of $P$. 
Table 1 Preliminary phytochemical results for Dichrostachys cinerea and Commiphora africana

\begin{tabular}{|c|c|c|c|c|c|c|c|c|}
\hline \multirow[t]{2}{*}{ Phytochemical constituents } & \multicolumn{4}{|c|}{ DCM extracts } & \multicolumn{4}{|c|}{$\mathrm{MeOH}$ extracts } \\
\hline & CAS & CAB & DCS & $\mathrm{DCB}$ & CAS & CAB & DCS & DCB \\
\hline Alkaloids & - & - & - & - & ++ & + & - & - \\
\hline Steroids & +++ & +++ & ++ & + & - & - & - & - \\
\hline Cardiac glycosides & + & - & - & - & +++ & +++ & +++ & +++ \\
\hline Flavonoids & +++ & +++ & +++ & +++ & +++ & +++ & +++ & +++ \\
\hline Tannins & - & - & - & - & +++ & +++ & +++ & - \\
\hline Triterpenoids & - & - & - & - & +++ & ++ & +++ & ++ \\
\hline Saponins & +++ & +++ & +++ & +++ & +++ & ++ & + & +++ \\
\hline
\end{tabular}

CAS: Commiphora africana whole stem; CAB: Commiphora africana stem bark; DCS: Dichrostachys cinerea whole stem; DCB: Dichrostachys cinerea stem bark; (+++): strongly present; $(++)$ : moderately present; $(+)$ : weakly present; $(-)$ : absent

Table 2 In vitro antiplasmodial activity and cytotoxicity of crude extracts from Dichrostachys cinerea and Commiphora africana

\begin{tabular}{lllll}
\hline Extract & $\begin{array}{l}\mathbf{I C}_{\mathbf{5 0}} \text { on D6 } \\
(\boldsymbol{\mu g} / \\
\mathbf{m L} \pm \mathbf{S D})\end{array}$ & $\begin{array}{l}\mathbf{I C}_{\mathbf{5 0}} \text { on Dd2 } \\
(\boldsymbol{\mu g} / \\
\mathbf{m L} \pm \mathbf{S D})\end{array}$ & $\begin{array}{l}\mathbf{C C}_{\mathbf{5 0}} \\
\mathbf{o n ~ L L C - M K 2} \\
(\boldsymbol{\mu} \mathbf{g} / \mathbf{m L} \pm \mathbf{S D})\end{array}$ & $\begin{array}{l}\text { Selectivity } \\
\text { index } \\
\text { by D6 }\end{array}$ \\
\hline CAB-DCM & $4.54 \pm 1.80$ & $>1000$ & $>1000$ & 471.00 \\
CAS-DCM & $>1000$ & $>1000$ & $>1000$ & $\mathrm{ND}$ \\
CAB-MeOH & $>1000$ & $>1000$ & $>1000$ & $\mathrm{ND}$ \\
CAS-MeOH & $>1000$ & $>1000$ & 74.56 & $\mathrm{ND}$ \\
DCB-DCM & $2.37 \pm 0.86$ & $11.92 \pm 7.43$ & $34.65 \pm 8.36$ & 14.63 \\
DCS-DCM & $11.47 \pm 2.17$ & $>1000$ & $29.44 \pm 4.16$ & 2.57 \\
DCB-MeOH & $>1000$ & $>1000$ & $>1000$ & $\mathrm{ND}$ \\
DCS-MeOH & $2.96 \pm 1.87$ & $>1000$ & $178.35 \pm 371.30$ & 60.24 \\
QN & $0.05 \pm 0.01$ & $0.06 \pm 0.01$ & & \\
Triton & & & $2.44 \pm 0.82$ & \\
X-100 & & & & \\
\hline
\end{tabular}

Italic values represent anti-plasmodial activity

Plant part: CAS: Commiphora africana whole stem; CAB: Commiphora africana stem bark; DCS: Dichrostachys cinerea whole stem; DCB: Dichrostachys cinerea stem bark

QN: quinine; ND: not determined; SD: standard deviation

falciparum. However, DCM extract of $D$. cinerea stem bark showed promising activity against both D6 and Dd2 strains of $P$. falciparum $\left(\mathrm{IC}_{50}=2.37 \pm 0.86 \mu \mathrm{g} / \mathrm{mL}\right.$ and $11.92 \pm 7.43 \mu \mathrm{g} / \mathrm{mL}$, respectively). The only methanolic extract with promising activity was that of $D$. cinerea whole stem $\left(\mathrm{IC}_{50}=2.96 \pm 1.87 \mu \mathrm{g} / \mathrm{mL}\right)$ against the $\mathrm{D} 6$ strain. According to the cytotoxic classification [16] all plant extracts were reported to be non-toxic to LLC-MK2 cells with $\mathrm{CC}_{50}$ of $>30 \mu \mathrm{g} / \mathrm{mL}$ except for DCM extract of $D$. cinerea whole stem which was reported to be weakly toxic $\left(\mathrm{CC}_{50}=29.44 \pm 4.16 \mu \mathrm{g} / \mathrm{mL}\right)$.

Findings from the in vivo anti-malarial study are summarized in Table 3. These results show that animals treated with the extracts had significantly higher survival rates during the 28 days of observation as compare to the control group, though lower than the one in which quinine was used. These groups also experienced a steady constant increase in body weight, and parasite suppression rates above $50 \%$.

\section{Discussion}

Plant extracts of D. cinerea and C. africana were screened for presence of phytochemicals which were then tested for anti-malarial activity against $P$. falciparum strains and cytotoxicity on LLC-MK2 monkey kidney epithelial cells. The methanol solvent showed high levels of phytoconstituents extracted, with strong presence of polar phytoconstituents such as tannins, cardiac glycosides and flavonoids. Dhawan and Gupta also reported that

Table 3 In vivo anti-malarial activities of crude extract of Dichrostachys cinerea and Commiphora africana in the Peters' suppressive test

\begin{tabular}{lllc}
\hline Treatment & Parasite suppression rate (\%) & Change in body weight (initial-final in grams) & Mean survival days \\
\hline Control & 0.00 & $-17.9 \%(23.5 \pm 1.1-19.3 .0 \pm 1.4)$ & $12.2 \pm 2.5$ \\
CAB-DCM & $64.24 \pm 1.43$ & $5.8 \%(22.4 \pm 0.6-23.7 \pm 1.2)$ & $23.0 \pm 3.5$ \\
DCB-DCM & $53.12 \pm 2.02$ & $3.9 \%(22.1 \pm 1.0-22.9 \pm 1.1)$ & $22.3 \pm 3.05$ \\
Quinine & $96.02 \pm 5.00$ & $7.2 \%(20.8 \pm 1.5-22.3 \pm 1.0)$ & $28.0 \pm 0.0$ \\
\hline
\end{tabular}

Mean and standard deviation values were generated from five replicates of each assay

CAB-DCM: dichloromethane extract of Commiphora africana bark; DCB-DCM: dichloromethane extract of Dichrostachys cinerea bark 
methanol as an extraction solvent worked best for the extraction of various active phytochemicals [18].

From the studied medicinal plants extracts, C. africana showed a higher diversity of phytoconstituents than $D$. cinerea. Flavonoids and saponins were strongly present in both plants and these findings are consistent with similar studies conducted in Zimbabwe and Burkina Faso [19, 20]. Alkaloids on the other hand, were weakly or moderately present only in the $C$. africana plant. A plausible explanation for this could be because alkaloids are known to exist in large proportions in the seeds and roots [21], whereas in this study the plant parts used were the stem bark and whole stem. Additionally, some phytochemicals are known to possess various pharmacological effects and may be responsible for various actions in $D$. cinerea and C. africana. For example, previous studies have reported that flavonoids possess notable antioxidant activity [22] and saponins having anti-inflammatory activities [23].

There are several strategies that are available for the discovery of new anti-malarial drugs and therefore identification of traditionally used plants extracts exhibiting $\mathrm{IC}_{50}$ values of less than $15 \mu \mathrm{g} / \mathrm{mL}$ are important first steps in the search for new anti-malarial plant extracts. In our study $D$. cinerea extracts exhibited high in vitro antiplasmodial activity, with the DCM stem bark extract having promising activity $(2.37 \pm 0.86$ and $11.92 \pm 7.43 \mu \mathrm{g} / \mathrm{mL}$, respectively) against both $C Q$ sensitive (D6) and CQ resistant (Dd2) strains and was also found to be noncytotoxic to the LLC-MK2 cells $34.65 \pm 8.36 \mu \mathrm{g} / \mathrm{mL}$. Therefore, the findings against $\mathrm{CQ}$ resistant $P$. falciparum parasites and non-toxic results to LLC-MK2 cells suggest that the extract can be a potential source for the isolation of safe and effective anti-malarial lead compounds. Similar studies conducted in South Africa, also reported $D$. cinerea to have promising antiplasmodial activity of $2.10 \mu \mathrm{g} / \mathrm{mL}$ against NF54 of P. falciparum [24].

The DCM extract of $D$. cinerea whole stem (DCS$\mathrm{MeOH})$ had promising antiplasmodial activity $(11.47 \pm 2.17 \mu \mathrm{g} / \mathrm{mL})$, however it was found to be weakly cytotoxic $(29.44 \pm 4.16 \mu \mathrm{g} / \mathrm{mL})$ and a selectivity index of 2.57, which suggests that the promising anti-malarial activity noticed was probably due to cytotoxicity rate than activity against the $P$. falciparum parasites per se.

The methanol crude extract of $D$. cinerea whole stem also had promising antiplasmodial activity $(2.96 \pm 1.87 \mu \mathrm{g} / \mathrm{mL})$ and this plant extract contained the majority of phytoconstituents selected. Perhaps, the synergism among the phytoconstituents that comprise the extract could explain the in vitro antiplasmodial activity. Surprisingly, most of the C. africana extracts were inactive despite their traditional use as anti-malarials by the Maasai. Its low activity could be due to variation in the active constituents possibly related to seasonal or geographical setting and also ability of phytoconstituents to mask the activity of other phytoconstituents which may result in reduction of the activity of the extract [25]. However, the DCM extract of the bark exhibited the highest effectiveness in $P$. berghei-infected mice, with up to $64.24 \%$ parasite suppression rate, as compared to $53.12 \%$ observed with the DCM extract of the $D$. cinerea stem bark. The decline in parasite growth and/or multiplication also reflected as significant weight recovery and survival rate, as compared to the control group. These activities demonstrated in the animal model therefore reinforce the likelihood of these two plants to serve as important sources of new anti-malarial therapies. Further investigations are urgently envisaged, as there is no published work on anti-malarial and cytotoxicity activity of C. africana so far.

\section{Conclusion}

In conclusion, this study has shown the pharmacological basis of the two plants that the Maasai in Arusha region in Tanzania use to treat suspected cases of malaria. In particular the antiplasmodial activity of dichloromethane, stem bark extract of $D$. cinerea showed good in vitro activity against the $P$. falciparum chloroquine resistant strain. The ability of this preparation to kill chloroquine resistant parasite strains is of value where chloroquine resistant malaria is in existence. Also there was a significant parasite suppression and disease recovery ability in $P$. berghei animal model. In addition, methanol extracts of $D$. cinerea (DCS-MeOH) had a cytotoxic concentration $\left(\mathrm{CC}_{50}\right)$ of $178.35 \mu \mathrm{g} / \mathrm{mL}$, suggesting that the plant extracts can be used to develop usable anti-malarials. Consequently, further work including bioassay-guided fractionation, and toxicity testing are recommended that can yield new anti-malarial drug candidates.

\section{Abbreviations \\ DCM: dichloromethane; DMEM: Dulbecco's Modified Eagle's medium; CC $_{50}$ : $50 \%$ cytotoxic concentration; $\mid \mathrm{C}_{50}: 50 \%$ inhibitory concentration; $\mathrm{MeOH}$ : methanol; RPMI: Roswell Park Memorial Institute.

\begin{abstract}
Authors' contributions
PAK and NE contributed in performing the laboratory work, analysis of data and drafting the manuscript. DZ and JCNA read and contributed to the laboratory training, data analysis and drafting the paper. JK provided significant editorial assistance. MN mentored and supervised the entire work. All authors read and approved the final manuscript.
\end{abstract}

\section{Author details}

${ }^{1}$ Department of Parasitology and Entomology, Kilimanjaro Christian Medical University College, P. O. Box 2240, Moshi, Tanzania. ${ }^{2}$ Medical Research and Applied Biochemistry Laboratory (Drug Discovery and Development Research Unit), University of Buea, P.O. Box 63, Buea, South West Region, Cameroon. 


\section{Acknowledgements}

Authors are very grateful to Dr. P.A. Kweyamba for the financial support. We are grateful to Mr. Smith Babiaka for contributing to the phytochemical analysis and preparation of crude extracts. We would also like to extend our gratitude to Mr. Emmanuel Mboya for helping with the identification of plants. The malaria parasite strains (P. falciparum D6, P. falciparum W2 and P. berghei) used in this work were kindly donated by BEI-Resources (Manassas, VA, USA).

\section{Competing interests}

The authors declare that they have no competing interests.

\section{Availability of data and materials}

All data generated and analysed are included in this research article.

\section{Consent for publication}

Not applicable.

\section{Ethics approval and consent to participate}

This study received ethical clearance (Ref. No. 2035) from the College Research Ethics Review Committee (CRERC) of the Kilimanjaro Christian Medical University College.

\section{Funding}

This work received financial support from Dr. P.A. Kweyamba. Equally, the in vivo testing was materially supported by Research Grant awarded to Dr. Denis Zofou, by The World Academy of Sciences (TWAS Grant No: 14-150 RG/ BIO/AF/AC_I - UNESCO FR: 324028598) and the International Foundation for Science (IFS Grant No. F/5122-2F)

\section{Publisher's Note}

Springer Nature remains neutral with regard to jurisdictional claims in published maps and institutional affiliations.

Received: 27 November 2018 Accepted: 28 March 2019

Published online: 04 April 2019

\section{References}

1. WHO. World malaria report 2016. Geneva: World Health Organization; 2016.

2. WHO. World malaria report 2017. Geneva: World Health Organization; 2017.

3. MoHSW. Tanzania National Malaria Strategic Plan 2014-2020. 2014.

4. Tanzania demographic and health survey and malaria indicator survey (TDHS-MIS). 2015-2016.

5. WHO. The African health monitor: African traditional medicine day. Geneva: World Health Organization; 2010.

6. Nondo RSO, Zofou D, Moshi MJ, Erasto P, Wanji S, Ngemenya MN, et al. Ethnobotanical survey and in vitro antiplasmodial activity of medicinal plants used to treat malaria in Kagera and Lindi regions, Tanzania. J Med Plants Res. 2015;9:179-92.

7. Evans WC. Trease and Evans' pharmacognosy. 11th ed. London: Bailliere Tindall; 1989.
8. Christen Y. Oxidative stress and Alzheimer disease. Am J Clin Nutr. 2000;71:621S-9S.

9. Young IS, Woodside JV. Antioxidants in health and disease. J Clin Pathol. 2001;54:176-86.

10. MacNee W. Pulmonary and systemic oxidant/antioxidant imbalance in chronic obstructive pulmonary disease. Proc Am Thorac Soc. 2005;2:50-60.

11. Trager W, Jensen JB. Human malaria parasites in continuos culture. Science. 1976;193:673-5.

12. Zofou D, Kowa KT, Wabo HK, Ngemenya MN, Tane P, Titanji VPK. Hypericum lanceolatum (Hypericaceae) as a potential source of new antimalarial agents: a bioassay-guided fractionation of stem bark. Malar J. 2001:10:167.

13. Makler MD, Hinrichs DJ. Measurement of the lactate dehydrogenase activity of Plasmodium falciparum as an assessment of parasitaemia. J Trop Med Hyg. 1993;48:205-10.

14. Malebo HM, Tanja W, Cal M, Swaleh SAM, Omolo MO. Antiplasmodial, anti-trypanosomal, anti-leishmanial and cytotoxicity activity of selected Tanzanian medicinal plants. Tanzan J Health Res. 2009;11:226-34.

15. Fidock DA, Rosenthal PJ, Croft SL, Brun R, Nwaka S. Antimalarial drug discovery: efficacy models for compound screening. Nat Rev Drug Discov. 2004;3:509.

16. Peters W, Portus $H$, Robinson L. The four-day suppressive in vivo antimalarial test. Ann Trop Med Parasitol. 1975;69:155-71.

17. Waako P, Gumede B, Smith P, Folb P. The in vitro and in vivo antimalarial activity of Cardiospermum halicacabum L. and Momordica foetida Schumch Et. Thonn. J Ethnopharmacol. 2005:99:137-43.

18. Dhawan D, Gupta J. Comparison of different solvents for phytochemical extraction potential from Datura metel plant leaves. Int J Biol Chem. 2017;11:17-22.

19. Viol DI. Screening of traditional medicinal plants from Zimbabwe for phytochemistry, antioxidants, antimicrobial, antiviral and toxicological activities. MPhil, University of Zimbabwe; 2009.

20. Compaore M, Meda RN, Bakasso S, Vlase L, Kiendrebeogo M. Antioxidative, anti-inflammatory potentials and phytochemical profile of Commiphora africana (A. Rich.) Engl. (Burseraceae) and Loeseneriella africana (Celastraceae) stem leaves extracts. Asian Pac J Trop Biomed. 2016;6:665-70.

21. Doughari JH. Phytochemicals: extraction methods, basic structures and mode of action as potential chemotherapeutic agents. In: Rao V, editor. Phytochemicals - a global perspective of their role in nutrition and health. London: InTechOpen; 2012.

22. Pietta PG. Flavonoids as antioxidants. J Nat Prod. 2000;63:1035-42.

23. Wang JR, Zhou H, Jiang ZH, Wong YF, Liu L. In vivo anti-inflammatory and analgesic activities of a purified saponin fraction derived from the root of Ilexpubescens. Biol Pharm Bull. 2008;31:643-50.

24. Bapela J, Meyer M, Kaiser M. In vitro antiplasmodial screening of ethnopharmacologically selected South African plant species used for the treatment of malaria. J Ethnopharmacol. 2014;156:370-3.

25. Weenen H, Nkunya MH, Bray DH, Mwasumbi LB, Kinabo LS, Kilimali VA. Antimalarial activity of Tanzanian medicinal plants. Planta Med. 1990;56:368-70.

Ready to submit your research? Choose BMC and benefit from:

- fast, convenient online submission

- thorough peer review by experienced researchers in your field

- rapid publication on acceptance

- support for research data, including large and complex data types

- gold Open Access which fosters wider collaboration and increased citations

- maximum visibility for your research: over 100M website views per year

At BMC, research is always in progress.

Learn more biomedcentral.com/submissions 